\title{
The relationship between sleep, nutrition and mood: a study of patients with anorexia nervosa
}

\author{
A. H. CRISP \\ EDWARD StoNEHILL
}

Academic Department of Psychiatry, St George's Hospital, Tooting, London, S.W.17

\author{
George W. Fenton \\ Institute of Psychiatry, \\ De Crespigny Park, London, S.E.5
}

\begin{abstract}
Summary
An initial observation that insomnia, especially early morning waking, is a feature of anorexia nervosa has been confirmed. A further proposition that the insomnia is more closely related to the nutritional disturbance than to the mood state has also been confirmed using standardized measures of weight, sleep and mood. These findings are discussed in terms of the possible relevance to other illnesses involving weight change in which there is an alteration of sleep patterns.
\end{abstract}

\section{Introduction}

Insomnia is a common complaint in patients with psychiatric illness. Such sleep difficulty is often thought to be mainly and directly related to the associated mental state, such as anxiety, and depression (Mayer-Gross, Slater \& Roth, 1960). Early morning waking in particular has been described as a feature of 'endogenous' depression and is regarded by some psychiatrists as a cardinal symptom differentiating this disorder from 'reactive' depression (Carney, Roth \& Garside, 1965). However, sleep disturbance, including early morning waking, has been described by others (McGhie, 1966; Willis, 1965) as a more general phenomenon in psychiatric illness, although severely depressed patients often complain of it more than others (Samuel, 1964). Severely depressed patients are also sometimes agitated and restless and have lost considerable weight (Hinton, 1962; Kiloh \& Garside, 1963). Clinically it has been noted that patients with primary anorexia nervosa frequently sleep badly, especially in terms of interrupted sleep and early morning waking, although they rarely complain of it (Crisp, 1967). Such patients suffer a severe disorder of weight loss associated with carbohydrate starvation, probably as a constitutionally and experientially derived neurotic psychosomatic response to adolescent emotional difficulties. In a systematic study of sixty patients with anorexia nervosa, Crisp (1967) reported that sleep disturbance together with other manifestations of increased arousal such as diffuse restlessness, tended to be a feature of more severe cases. It was not clearly related to factors such as age, duration of illness, feeding pattern or type of diet and could not be explained as a result of affective disturbance. Only ten patients of the whole series showed evidence of clinical depression. It was concluded that the sleep disturbance was directly related to the malnutrition, and it was suggested that nutritional factors may play a significant role in the genesis of insomnia in other more common psychiatric conditions, especially depressive illness.

The present investigations were undertaken in order to examine in greater detail these clinical observations by a longitudinal study of two groups of anorexia nervosa patients, each patient acting as her own control. The first group was examined by means of sleep self-reports before treatment and after restoration of body weight, and the second group by continuous all-night EEG recordings before and after treatment.

\section{Sleep self-reports \\ Method}

Ten female inpatients of mean age $22 \pm 4$ years suffering from anorexia nervosa slept for five nights each in a single quiet room before treatment and again after their weight had been restored to normal levels. Treatment consisted of bedrest, chlorpromazine, re-feeding on a 3000 calorie 'normal' diet and weekly psychotherapy according to the regime 
described by Crisp (1965). Nine of the patients received no night sedation and the tenth patient received the same hypnotic after treatment as before. The post-treatment investigation was carried out after patients had been taken off phenothiazines at least 2 weeks previously. All patients achieved their matched population mean weight during treatment.

Each patient retired to bed between 10.00 p.m. and 10.30 p.m. and was left to wake spontaneously in the morning. In the morning the patient was required to complete a questionnaire (Crisp \& Stonehill, 1970) enquiring about the previous night's sleep. During the investigation periods, the patient completed two questionnaires measuring psychoneurotic status and personality, namely the Middlesex Hospital Questionnaire (MHQ) and the Eysenck Personality Inventory (EPI). The MHQ (Crown \& Crisp, 1966) is a brief standarized psychoneurotic index. It comprises a printed questionnaire of forty-eight questions completed by the patient. Responses provide scores (0-16) on six scales of psychoneurotic status, namely an anxiety (anx:) scale, a phobic (pho:) scale, an obsessional (obs:) scale, a scale measuring somatic complaints (som:), a depression (dep:) scale and an hysteria (hys:) scale. The EPI (Eysenck \& Eysenck, 1964) measures personality along the dimensions of neuroticism $(\mathrm{N})$ and introversion-extroversion (E). In addition each patient was weighed on accurate weighing scales during the two periods of investigation. In order to allow for adjustment to the experimental conditions, the sleep questionnaires on the first two nights of each five-night period were discarded.

\section{Results}

Mean values of the various sleep items were calculated for the last three nights of each five-night period before and after treatment for the ten patients. Table 1 shows the mean pre-treatment and posttreatment values for weight, sleep items, MHQ and EPI scores on the ten patients. The mean group weight increased from $39.9 \mathrm{~kg}$ to $54.4 \mathrm{~kg}$, a highly significant increase in weight $(P<0.001)$. The group mean total duration of sleep per night increased from just over $6 \frac{1}{2} \mathrm{hr}$ to just over $7 \frac{1}{2} \mathrm{hr}$ and this is significant at the $1 \%$ level. It is apparent that the mean group total change in sleep reflects changes occurring throughout the night; the pre-treatment delay in falling asleep of over $1 \mathrm{hr}$ falling to just over $\frac{1}{2} \mathrm{hr}$ in the post-treatment period; the mean 3 pre-treatment reported duration of interrupted sleep falling from $16 \mathrm{~min}$ to $7 \mathrm{~min}$ post-treatment; similarly final waking in the morning changing from of just after 6.00 a.m. pre-treatment to after $6.30 \mathrm{a} . \mathrm{m}$. N post-treatment. These differences failed to reach $\vartheta$ statistical significance with the numbers involved $ᄋ$ $(P<0 \cdot 10)$. On the MHQ all scales except the pho: and hys: revealed a decrease in mean score in the $\rightarrow$ post-treatment period but only the som: and dep: 을. scores reached significance $(P<0.05)$. However, these latter changes were contributed to by changef in scores on questions in both of the scales relating specifically to sleep. Moreover, none of the patiens was judged to be suffering from severe depression on clinical grounds during the pre-treatment period. Thus, when the pre-treatment MHQ scores of this group of patients are compared with the mean

TABLE 1. Mean weight, sleep patterns, psychiatric status personality and significance of difference in ten patients with anorexia nervosa before and after treatment

\begin{tabular}{|c|c|c|c|c|}
\hline & & Pre-treatment & Post-treatment & $\begin{array}{c}\text { Significance } \\
(P)\end{array}$ \\
\hline \multirow{2}{*}{\multicolumn{2}{|c|}{$\begin{array}{l}\text { Weight } \\
\text { Total sleep }\end{array}$}} & $39.9 \mathrm{~kg}$ & $54.4 \mathrm{~kg}$ & $<0.001$ \\
\hline & ep & $6 \mathrm{hr} 32 \mathrm{~min}$ & $7 \mathrm{hr} 35 \mathrm{~min}$ & $<0.01$ \\
\hline \multicolumn{2}{|c|}{ Time to fall asleep } & $67.7 \mathrm{~min}$ & $38.5 \mathrm{~min}$ & $<0 \cdot 10$ \\
\hline \multicolumn{2}{|c|}{ Broken sleep } & $15 \cdot 8 \mathrm{~min}$ & $6.8 \mathrm{~min}$ & $<0 \cdot 10$ \\
\hline \multicolumn{2}{|c|}{ No. sleep interruptions } & $1 \cdot 27$ & $1 \cdot 06$ & NS \\
\hline \multicolumn{2}{|c|}{ Time of final waking } & $6 \cdot 10$ a.m. & $6 \cdot 38$ a.m. & $<0 \cdot 10$ \\
\hline \multicolumn{2}{|c|}{ Total time in bed } & $8 \mathrm{hr} 29 \mathrm{~min}$ & $8 \mathrm{hr} 54 \mathrm{~min}$ & NS \\
\hline \multicolumn{2}{|c|}{ Total time awake } & $127 \cdot 5 \mathrm{~min}$ & $77.5 \mathrm{~min}$ & $<0.02$ \\
\hline & Anxiety & $7 \cdot 1$ & $5 \cdot 0$ & $<0 \cdot 10$ \\
\hline & Phobic & $2 \cdot 5$ & $2 \cdot 7$ & NS \\
\hline & Obsessional & $9 \cdot 6$ & $8 \cdot 0$ & NS \\
\hline \multirow{4}{*}{ MHQ } & Somatic & $4 \cdot 6$ & $1 \cdot 5$ & $<0.05$ \\
\hline & Depression & $7 \cdot 5$ & $5 \cdot 2$ & $<0.05$ \\
\hline & Hysteria & $6 \cdot 1$ & $6 \cdot 3$ & NS \\
\hline & Total & $37 \cdot 8$ & $28 \cdot 8$ & $<0.05$ \\
\hline \multirow{2}{*}{ EPI } & $\mathbf{N}$ & $12 \cdot 1$ & $9 \cdot 6$ & NS \\
\hline & $\mathrm{E}$ & $6 \cdot 3$ & $12 \cdot 1$ & $<0.001$ \\
\hline
\end{tabular}

$\mathrm{N}$, neuroticism; E, introversion-extroversion. 
TABLE 2. Mean MHQ scores, standard deviations and significance of differences between ten inpatients with anorexia nervosa before treatment and twenty-four non-depressed psychoneurotic inpatients

\begin{tabular}{|c|c|c|c|c|c|c|}
\hline & A & $\mathbf{P}$ & 0 & $\mathbf{S}$ & D & $\mathbf{H}$ \\
\hline $\begin{array}{l}\text { Ten inpatients with anorexia nervosa } \\
\text { before treatment aged } 22 \pm 4 \text { years }\end{array}$ & $7 \cdot 5 \pm 3 \cdot 5$ & $2 \cdot 5 \pm 1 \cdot 9$ & $9 \cdot 6 \pm 3 \cdot 1$ & $4 \cdot 6 \pm 3 \cdot 1$ & $7 \cdot 5 \pm 2 \cdot 7$ & $6 \cdot 1 \pm 2 \cdot 7$ \\
\hline $\begin{array}{l}\text { Twenty-four non-depressed psycho- } \\
\text { neurotic inpatients aged } 30 \pm 9 \text { years }\end{array}$ & $12 \cdot 5 \pm 1 \cdot 8$ & $9 \cdot 0 \pm 4 \cdot 0$ & $9 \cdot 3 \pm 3 \cdot 0$ & $9 \cdot 3 \pm 4 \cdot 2$ & $8 \cdot 2 \pm 2 \cdot 7$ & $7 \cdot 5 \pm 3 \cdot 3$ \\
\hline Probability $(P)$ & $<0.001$ & $<0.001$ & NS & $<0.001$ & NS & NS \\
\hline
\end{tabular}

A, anxiety; P, phobic; O, obsessional; S, somatic; D, depression; H, hysteria.

MHQ scores of twenty-four psychoneurotic inpatients who were not diagnosed as suffering from depressive illness (Table 2), there is no difference in the dep: scores between the two groups. On the EPI there was a mean increase in the $\mathrm{E}$ score after treatment which is significant at the $0 \cdot 1 \%$ level.

During treatment all patients achieved their matched population mean weight but the weight increase necessary for this varied between patients. Table 3 is a chart displaying the changes between pre-treatment and post-treatment weights, sleep patterns, MHQ and EPI scores in the ten patients. When the amount of weight increase is correlated with each of the changes in sleep patterns (Table 4),

TABLE 4. Coefficients of correlation and significances between increase in weight and aspects of improved sleep in ten patients with anorexia nervosa during treatment

\begin{tabular}{lcc}
\hline Sleep item & $r$ & $P$ \\
\hline Total sleep & 0.56 & $<0 \cdot 1$ \\
Time to fall asleep & 0.06 & NS \\
Broken sleep (min) & $0 \cdot 16$ & NS \\
No. sleep interruptions & 0.33 & NS \\
Time of waking & 0.89 & $<0.001$ \\
\hline
\end{tabular}

the main and significant correlation (with the small numbers involved) is between amount of weight increase and later time of waking up in the morning $(r=0.89 ; P<0.001)$. Changes in weight, total sleep, time to fall asleep, interrupted sleep and time of final waking failed to correlate at a significant level with any of the MHQ and EPI score changes. When the correlation coefficient between increase in weight and later time of waking up in the morning is calculated with the effect of MHQ dep: score partialled out, it remains significant at the $0 \cdot 1 \%$ level $(r=0 \cdot 88)$.

\section{Continuous EEG recordings}

Five patients (four female and one male) admitted to a psychiatric metabolic unit for treatment of primary anorexia nervosa were examined. Their ages were 14, 16, 17 (male), 18 and 36 years. Each was seen 10-14 days after admission. At bedtime chlorided silver 'stick-on' electrodes were applied to the scalp in the right frontal, central, parietal and occipital areas as well as the superior and lateral aspects of both orbits. These were connected to an eight-channel Offner type $\mathrm{T}$ electroencephalograph in an adjacent room.

The patient then retired to bed and bipolar recordings were performed continuously throughout the night, for at least $7 \mathrm{hr}$ or longer until the patient woke spontaneously. This procedure was repeated during the following three nights, recordings being carried out on each patient during four consecutive nights. When the patients had gained weight, but not necessarily a weight amounting to their matched population weight, and prior to discharge from hospital, this procedure was repeated, each patient having a further four consecutive all-night sleep recordings performed. The interval between the two series of tests varied from 6 weeks to 3 months. Treatment consisted of re-feeding with a high protein and high carbohydrate diet. No daytime psychotropic drugs were prescribed. One patient received a hypnotic, the dose being maintained unchanged throughout the study. Four of the patients responded well to this regime, gaining at least $10 \mathrm{~kg}$. One failed to show any appreciable weight gain. Daily ratings of mood and behaviour were carried out using a modification of the Phipps behaviour chart (Russell, 1967) and each patient's mood was also assessed independently by a psychiatrist unaware of the EEG findings, during an interview conducted on the day of the first of each series of recordings.

All sleep records were examined by a single investigator, who rated the depth of sleep for each 20 -sec period throughout the night using the Loomis, Harvey \& Hobart (1937) classification. Data obtained from the first night of each fournight series were discarded in order to allow for the so-called 'first night effect', ratings from subsequent nights being used.

\section{Results}

Results obtained from the four patients who gained weight were examined separately, the fifth patient who gained no weight being treated as a 


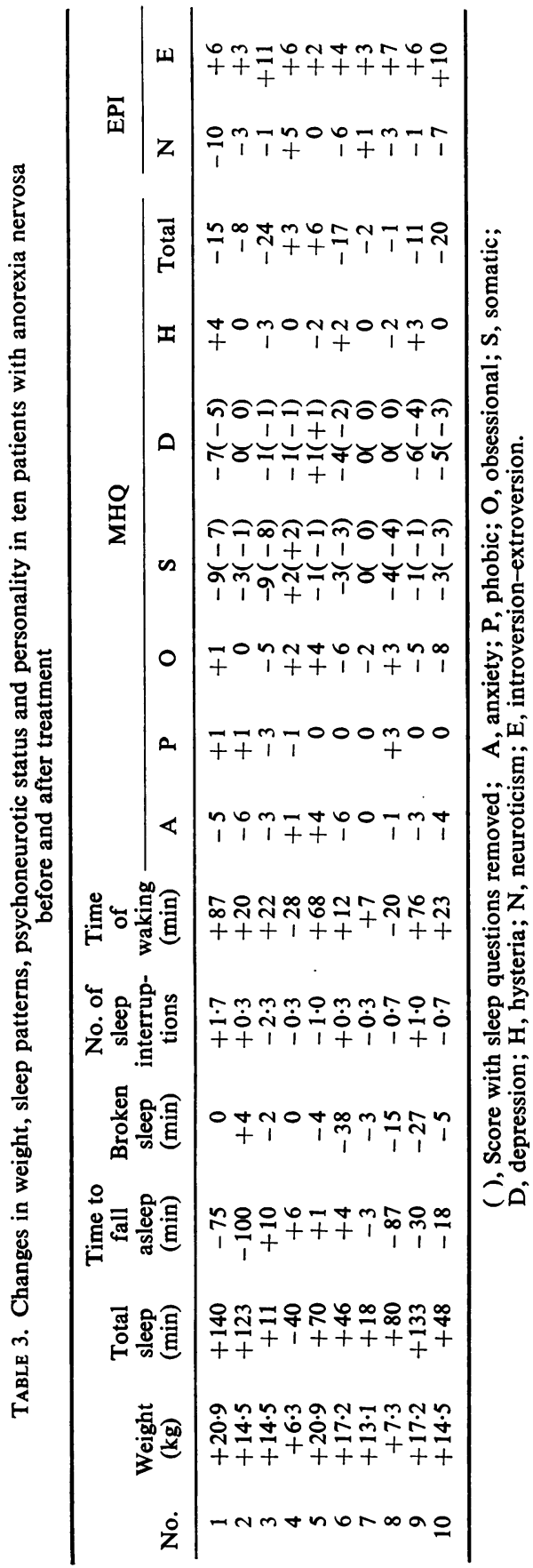


control subject. In the light of the initial observation and the results of the sleep self-report study, these large amounts of EEG data were treated so as to provide twelve separate items of information both before and after treatment on the four patients, the corresponding nights of investigation before and after treatment being compared on each occasion.

The total time asleep per night, defined as the duration of time spent in stages B (light sleep), C (medium sleep), D (deep sleep), E (very deep sleep) and REM (rapid eye movement sleep) was increased following treatment, the mean for the initial twelve nights being $6 \cdot 3 \mathrm{hr}$ compared with the post-treatment value of $7 \cdot 0 \mathrm{hr}$. This difference is significant at the $5 \%$ level.

Figure 1 displays in histogram form the amount of time spent in the various stages of sleep throughout the night, and Table 5 shows this data in tabular form with probability levels concerning the significance of the differences. Before treatment signi-

TABle 5. Time in each stage of sleep in minutes. Mean values for twelve nights in four subjects with anorexia nervosa

\begin{tabular}{cccc}
\hline Stage & $\begin{array}{c}\text { Before } \\
\text { treatment }\end{array}$ & $\begin{array}{c}\text { After } \\
\text { treatment }\end{array}$ & $\begin{array}{c}\text { Significance } \\
(P)\end{array}$ \\
\hline Awake & 28.5 & 5.9 & $<0.01$ \\
A & 27.9 & 3.1 & $<0.005$ \\
B & 88.8 & 93.4 & NS \\
C & 170.9 & 156.4 & NS \\
D & 65.2 & 89.1 & $<0.05$ \\
E & 33.5 & 73.4 & $<0.005$ \\
REM & 63.1 & 78.1 & $<0.05$ \\
\hline
\end{tabular}

ficantly more time was spent awake $(P<0.01)$ and in stage A (drowsy) $(P<0.005)$, whilst on retest an increase in duration of time spent in stages $D$ $(P<0.05)$ and E $(P<0.005)$ was apparent. The amount of REM sleep was also greater after refeeding $(P<0.05)$. The latency of onset of both slow wave and REM sleep was altered following weight gain. The mean length of time from the onset of the recording to the first $60 \mathrm{sec}$ of $\mathrm{C}$ stage sleep was significantly reduced from $27.4 \mathrm{~min}$ before treatment to $7.6 \mathrm{~min}$ after treatment $(P<0.025)$. The mean latency of onset of REM appeared to be delayed pretreatment and occurred after $147.5 \mathrm{~min}$ but was reduced to $77.6 \mathrm{~min}$ post-treatment $(P$ $>0.02$ ). The mean number of shifts of stage of sleep per hour was also reduced from 43.1 before treatment to $36 \cdot 1$ after treatment but this trend did not reach statistical significance. The amount of time spent awake during the night was greatest during the first and last hours, especially the latter (Fig. 2). Before treatment the mean total amount of time spent awake during the seventh hour of recording was $16.0 \mathrm{~min}$ and this was reduced to $8.2 \mathrm{~min}$ after treatment, but this trend did not reach statistical significance.

The patient whose weight remained essentially unchanged can be regarded as a control subject and Fig. 3 reveals that there was no major change in the sleep pattern.

Ratings of the patients' mood states carried out by the nursing staff and assessement of the mental state carried out by the psychiatrist before and after treatment revealed no consistent mood changes.

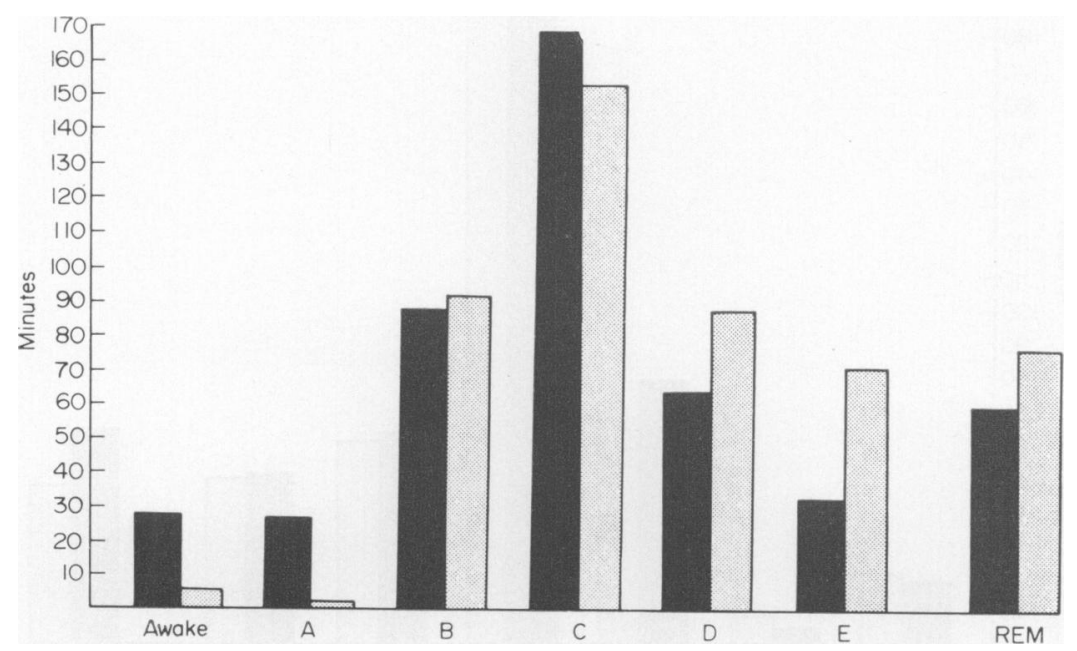

Fig. 1. Mean duration of each stage of sleep in anorexia patients (four subjects), twelve nights before treatment and twelve nights after treatment. Closed columns, before treatment; stippled columns, after treatment. 


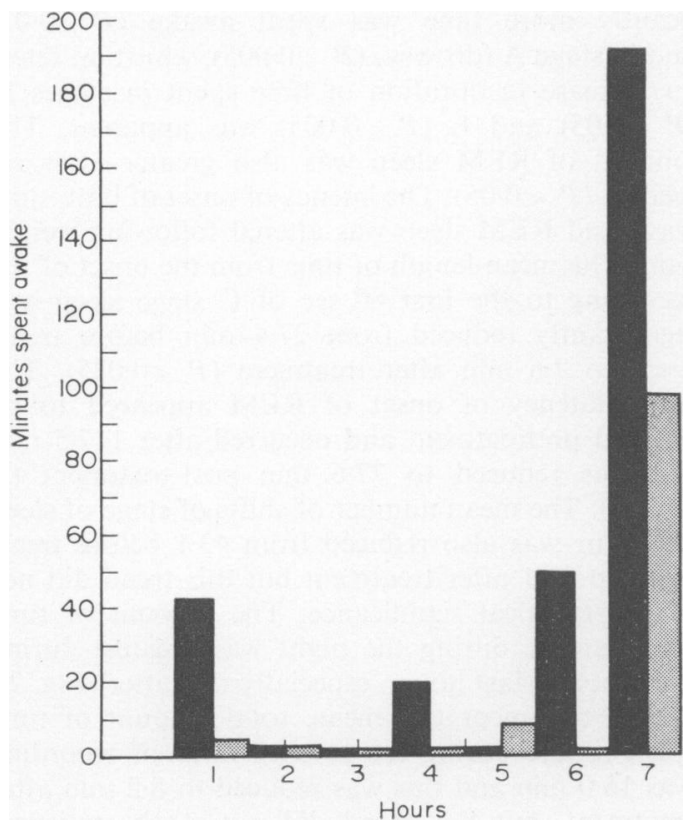

FIG. 2. Pattern of wakefulness throughout the night: the total number of minutes spent awake during each hour in twelve nights of all-night recording in four patients with anorexia nervosa. Closed columns, before treatment; stippled columns, after treatment.

One patient, initially depressed, showed improvement, while the other three were unchanged. The control patient also showed no mood change.

\section{Discussion}

These findings are taken to confirm the original observations concerning insomnia in patients with $\mathrm{c}_{\mathrm{C}}$ primary anorexia nervosa. They also lend support $\Rightarrow$ to the proposition that, in this group of patients, disturbances and changes in sleep are more closelyo associated with disturbances and changes in nutri-흐 tional status than with disturbances and changes in $\frac{\bar{c}}{\sigma}$ emotional state. This finding may relate to the $\stackrel{\mathbb{\Phi}}{\Omega}$ results reported in another study (Crisp \& Stonehill, 1970 ) in which obese patients losing weight showed evidence of increasing insomnia whilst at the same? time displaying improvement or no change in their $\overrightarrow{\vec{\omega}}$ mental state.

Such findings are taken to lend further support응 to the original proposition that such relationships 3 . might also hold for a variety of psychiatric and other disorders in which there is impaired nutritionalio status and weight loss.

Meanwhile, since there is a suggestion thati patients who develop anorexia nervosa whilst still $v$ undergoing pubertal change are shorter than $a$ 음 control population by the time they present todoctors with the illness later in adolescence (Crisp,,$\frac{D}{}$ 1969), it is of interest that it has been shown (Sassin et al., 1969) that release of human growth hormone $\vec{\omega}$ during sleep is significantly directly related to the presence of the slow synchronized EEG stages $\bar{z} f^{-}$ sleep, which it has now been shown are reduced amount in anorexia nervosa patients.

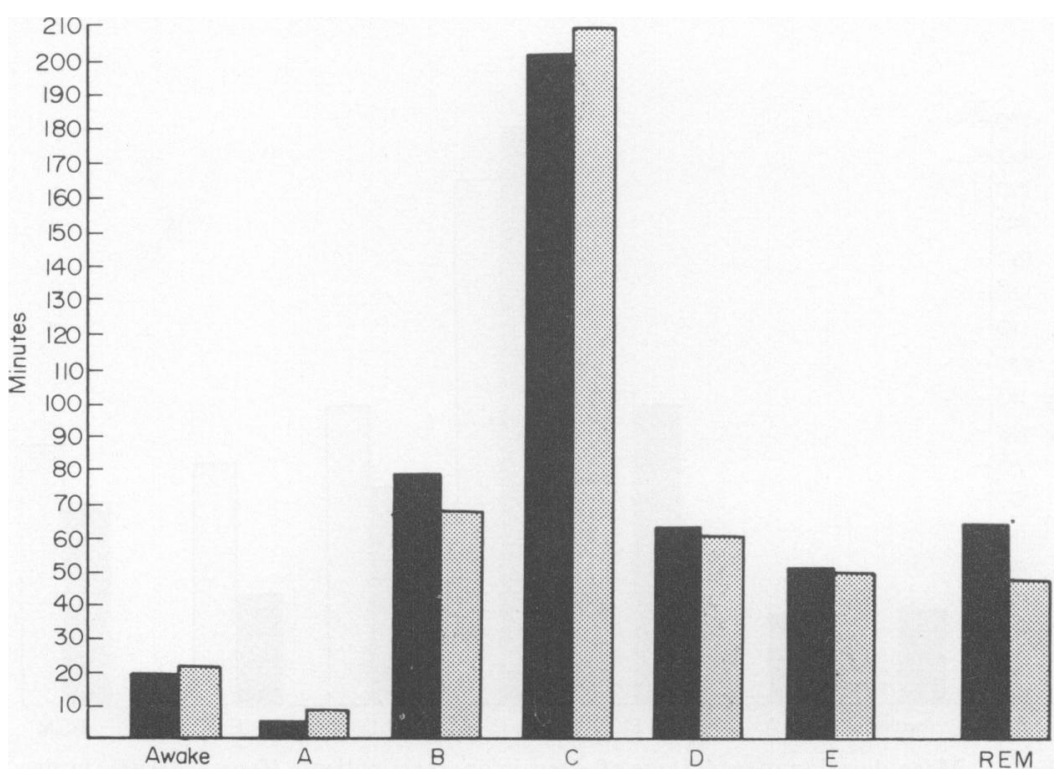

FIG. 3. Control subject: mean of three nights before and three nights after treatment. Closed columns, before treatment; stippled columns, after treatment. 


\section{Acknowledgments}

The authors would like to express their gratitude to Prof. G. F. M. Russell for permission to investigate the patients in study 2; also Dr P. Fenwick, research worker, and Mrs T. Elphicke, EEG technician, at the Institute of Psychiatry who also assisted in the second study. The first study, carried out in the psychiatric department of Atkinson Morley's Hospital, branch of St George's Hosnital, is part of a larger study supported by a grant from the Medical Research Council to A.H.C.

\section{References}

Carney, M.W.P., Roth, M. \& Garside, R.F. (1965) The diagnosis of depressive syndromes and the prediction of ECT response. British Journal of Psychiatry. iii, 659.

CRISP, A.H. (1965) A treatment regime for anorexia nervosa. British Journal of Psychiatry, 112, 505.

CRISP, A.H. (1967) The possible significance of some behavioural correlates of weight and carbohydrate intake. Journal of Psychosomatic Research, 11, 117.

CrisP, A.H. (1969) Some skeletal measurements in patients with primary anorexia nervosa. Journal of Psychosomatic Research, 13, 125.

CrisP, A.H. \& Stonehill, E. (1970) Sleep patterns, daytime activity, weight changes and psychiatric status: a study of three obese patients. Journal of Psychosomatic Research, 14, 353.

Crown, S. \& Crisp, A.H. (1966) A short clinical diagnostic self-rating scale for psychoneurotic patients: the Middlesex Hospital Questionnaire (MHQ). British Journal of Psychiatry, 112, 917.
EYSENCK, H.J. \& EYSENCK, S.B.G. (1964) Manual of the Eysenck Personality Inventory. University of London Press, London.

Hinton, J.M. (1962) Sleep: sleep and motility in depressive illness. Proceedings of the Royal Society of Medicines, 55, 907.

KILOH, L.G. \& Garside, R.F. (1963) The independence of neurotic depression and endogenous depression. British Journal of Psychiatry, 109, 451.

Loomis, A.L., Harvey, E.N. Hobart, G.A. (1937) Cerebral states during sleep as studied by human brain potentials. Journal of Experimental Psychology, 21, 127.

Mayer-Gross, W., Slater, E. \& Roth, M. (1960) Clinical Psychiatry, p.204. Cassell, London.

McGhiE, A. (1966) The subjective assessment of sleep patterns in psychiatric illness. British Journal of Medical Psychology, 39, 221.

Russell, G.F.M. (1967) The nutritional disorder in anorexia nervosa. Journal of Psychosomatic Research, 11, 141.

SAMUEL, J.G. (1964) Sleep disturbance in depressed patients: objective and subjective measures. British Journal of Psychiatry, 110, 711.

Sassin, J.F., Parker, D.C., Mace, J.W., Gotlin, R.W., Johnson, L.C. \& Rossman, L.G. (1969) Human growth hormone release: relation of slow-wave sleep and sleepwaking cycles. Science, 165, 513.

Willis, J.H.P. (1965) Insomnia in psychiatric patients. Guy's Hospital Reports, 114, 249. 